\title{
DISCURSOS DO/SOBRE O BAIRRO SÃO GERALDO/ATERRADO NA CIDADE DE POUSO ALEGRE $^{1}$
}

\author{
ANDRÉ SILVA BARBOSA ${ }^{2}$ \\ Programa da Pós-Graduação em Linguística. Instituto de Estudos da Linguagem \\ Universidade Estadual de Campinas \\ Rua Sérgio Buarque de Holanda, 571. 13083-859. Campinas, SP - Brasil
}

andrergroundehotmail.com

\begin{abstract}
Resumo: Esta pesquisa é sobre o bairro São Geraldo da cidade de Pouso Alegre (MG), também conhecido popularmente como Aterrado. Tendo em vista que ele está localizado em uma região central na cidade, e que desde a sua formação até os dias atuais ele vem sendo constituído pela falta do Estado em seu espaço, a partir do campo teórico da Análise de Discurso, o nosso objetivo geral foi compreender o modo como o bairro é significado na cidade em tais condições de produção. Especificamente, analisamos esse processo de significação trabalhando com determinados discursos sobre o São Geraldo/Aterrado e também com discursos do próprio bairro.
\end{abstract}

Palavras-chave: São Geraldo; aterrado; Pouso Alegre; discurso (do) urbano; discurso da cidade.

\begin{abstract}
It is a research about São Geraldo neighborhood from Pouso Alegre city, also popularly known as Aterrado. Since this neighborhood is located in a central region of the city and from the formation of the city until the current days it is being constituted by the lack of the state in its space, using the theoretical field of Discourse Analysis, our general aim is to understand the way the neighborhood is signified in the city in such conditions of productions. Specifically, we analyze this process of signification working with determined discourses about São
\end{abstract} Geraldo/Aterrado and also with discourses about the own neighborhood.

Keywords: São Geraldo; Aterrado; Pouso Alegre; discourse (of) urban; discourse of the city.

\footnotetext{
${ }^{1}$ Este artigo é um dos resultados do nosso trabalho de mestrado, intitulado "São Geraldo: Aterrado de Sentidos", que foi desenvolvido no Programa de Pós-Graduação em Ciências da Linguagem da Universidade do Vale do Sapucaí, sob orientação da Prof ${ }^{a}$. Dr ${ }^{a}$. Eni Orlandi, e que contou com o apoio da Fundação de Amparo à Pesquisa do Estado de Minas Gerais.

2 Doutorando em Linguística no Programa de Pós-Graduação em Linguística do Instituto de Estudos da Linguagem da Universidade Estadual de Campinas, e bolsista do CNPq.
} 


\section{Introdução}

No presente artigo, realizamos um estudo sobre o bairro São Geraldo, que também é conhecido popularmente como Aterrado. A partir da Análise de Discurso, analisamos discursos do e sobre o referido bairro. Buscamos expor e compreender o modo como ele é significado na cidade, tanto pelos seus moradores como por aqueles que não o são. Uma das características constitutivas desse bairro, que no nível local faz dele uma particularidade, está ligada ao seu posicionamento geográfico na cidade relacionado às suas condições sociais, infraestruturais e simbólicas.

Podemos afirmar que o São Geraldo foi constituído pela "falta do Estado" (ORLANDI, 2012). Ao consultarmos fontes históricas sobre a cidade, observamos que o bairro é um dos mais antigos em Pouso Alegre, e que a região em que está localizado, atualmente central, era inicialmente uma zona periférica (GOUVÊAA, 2004). Porém, diferentemente de outros locais que no começo da formação da cidade também eram áreas afastadas do centro, ao longo do tempo ele não recebeu, por parte do Estado, intervenções que promovessem melhorias significativas em seu espaço, ou mesmo que sanassem necessidades básicas dos seus moradores em todo o seu domínio. Com o passar dos anos, as suas condições estruturais, ambientais, sanitárias e sociais permaneceram precárias (FARIA, 2008). Nos dias atuais ainda encontramos no bairro casas em que não há tratamento de esgoto, água encanada, ruas em que faltam a coleta de lixo, a limpeza e o calçamento. Com o passar dos anos, o São Geraldo permaneceu em condições que geralmente são mais comuns às periferias urbanas, mesmo tendo se tornando um bairro central. No seu caso, esse processo aconteceu de forma distinta da de outras localidades que também passaram por essa mudança, isto é, da de lugares que antes eram áreas afastadas do centro e marginalizadas pela população e que atualmente são regiões centrais e valorizadas na cidade, como, por exemplo, segundo nos diz Gouvêa (2004), o antigo Morro das Cruzes. Podemos dizer que, ao contrário do seu posicionamento, além dos aspectos infraestruturais, os sentidos do São Geraldo também continuaram à margem, e consideramos que a hostilidade com a qual ele muitas vezes é tratado é intensificada justamente por ele permanecer em condições precárias mesmo tendo se tornado um bairro geograficamente central. De uma maneira resumida, estes são alguns dos pontos que despertaram o nosso interesse em desenvolver um estudo discursivo sobre o São Geraldo.

Segmentamos as nossas análises em duas etapas. Primeiramente, buscando compreender determinados "discursos sobre o bairro", que para nós estão funcionando enquanto "discurso (do) urbano", "discurso sobre a cidade" (ORLANDI, 1999), elencamos uma imagem referente ao São Geraldo que foi formulada na rede social do Facebook pela página denominada Pouso Alegre da Depressão e também alguns recortes da seção do site Desciclopédia que é dedicada a Pouso Alegre. Na etapa seguinte, visando abordar o "discurso do bairro", o qual estamos considerando ainda como "discurso da cidade" (IBIDEM), conforme explicitaremos a seguir, analisamos uma matéria do jornal Folha do Vale, na qual é noticiado um acontecimento denominado Semana do Bairro, que foi organizado pelos moradores do São Geraldo e pelos integrantes da Associação do bairro, chamada Viva Geraldo! 


\section{Discussão teórica}

Os dois segmentos nos quais dividimos as nossas análises estão relacionados às categorias de discursos que formulamos para esta pesquisa: discurso do/sobre o São Geraldo. Antes de prosseguirmos, consideramos importante expor a maneira como estamos realizando esta demarcação.

Tendo em vista o modo de configuração do nosso estudo, é certo que todos os discursos que escolhemos para análise, de alguma maneira, sempre fazem referência ao bairro. Assim, ressaltamos que, ao dizermos "discurso sobre", a definição que seguimos não é exatamente em relação ao seu referente, visto que mesmo no "discurso do" o bairro também está presente. E, por outro lado, ao falarmos "discurso do São Geraldo", não necessariamente estamos nos reportando aquele feito por um sujeito que reside no bairro. Ou seja, essas categorias não estão sendo compreendidas estritamente de acordo com o objeto dos discursos que analisamos e nem mesmo segundo o local da cidade que os sujeitos que os realizaram moram. A definição dos discursos "do" e "sobre" o São Geraldo foi estabelecida por nós a partir de determinados conceitos do nosso campo teórico.

Como explica Orlandi (2009, p. 40), “em toda língua há regras de projeção que permitem ao sujeito passar da situação (empírica) para a posição (discursiva)" e "o que significa no discurso são essas posições". Acompanhando essas palavras, primeiramente, especificamos que o discurso do São Geraldo não está sendo tratado de acordo com a situação (empírica), mas sim com a posição (discursiva). Quer dizer, ele não é exclusivamente feito por alguém que vive no bairro, mas sim por um sujeito que, no discurso, se posiciona como sendo do São Geraldo. Pêcheux (2009, p. 150) nos diz que "a interpelação do indivíduo em sujeito de seu discurso", processo através do qual resulta justamente a posição sujeito, "se efetua pela identificação (do sujeito) com a formação discursiva que o domina (isto é, na qual ele é constituído como sujeito)". A partir dessa colocação, acrescentamos que a posição sujeito do bairro é marcada pela sua identificação com a formação discursiva que lhe corresponde, a qual poderíamos chamar formação discursiva do bairro.

Uma melhor compreensão da definição dessa formação discursiva, e consequentemente da sua respectiva posição sujeito, nos é possibilitada pelo procedimento com o qual também assinalamos o discurso sobre o São Geraldo. Para isso, consideramos as diferentes formas do "discurso urbano" com as quais trabalhamos em Análise de Discurso. De acordo com Orlandi, há uma distinção entre a "ordem" e a "organização" da cidade. Segundo ela (2001, p. 13), a primeira é "do domínio do simbólico na relação com o real da história (a sistematicidade sujeita a equívoco)", já a segunda refere-se "ao empírico e ao imaginário (o arranjo das unidades)". A autora (1999, p. 10) nos fala que, atualmente, o "real da cidade" vem sendo sobreposto pelo "conhecimento sobre a cidade", este, que é produzido tanto na "forma erudita (discurso do urbanista)", quanto na do "senso comum em que esse discurso do urbanista é incorporado pelo político, pelo administrador, pela "comunidade". Orlandi conceitua esse discurso "sobre a cidade", que é justamente do âmbito da "sobreposição", da "organização" e do "imaginário", como "discurso (do) urbano", distinguindo-o do "discurso da cidade", que, por sua vez, é aquele que significa a cidade em seu real. 
Foi com base nestas colocações que demarcamos o discurso sobre o São Geraldo, apreendendo como tal aqueles que funcionam como "discurso (do) urbano" (ibidem) ao significarem o bairro: que se filiam a uma formação discursiva de "organização" da cidade; discursos em que pudemos observar que há a sobreposição da "materialidade", do "real da cidade" a partir do "imaginário" (do) urbano sobre ela. Quanto ao "discurso do São Geraldo", que, como dissemos, não é necessariamente realizado por seus moradores, mas por sujeitos que se posicionam discursivamente como sendo do bairro, observamos que, nos materiais que analisamos, ele se apresenta enquanto uma forma de "discurso da cidade" (ibidem). Afinal, ele abarca aqueles em que não há a contenção da falha, da contradição e do equívoco que são constitutivos do espaço urbano, que não são, em prol da "organização", marcados pelo silenciamento, mas sim filiados a uma formação discursiva que faz significar os sentidos do "real da cidade" ou, neste caso, do "real do bairro". Como veremos, eles estão funcionando como uma das materialidades pelas quais o bairro se significa em seu real.

\section{Discurso sobre o bairro}

Nesta primeira etapa das análises, apreenderemos o discurso sobre o São Geraldo. Visamos compreender como o bairro é significado em determinados discursos que funcionam a partir do "imaginário urbano" de "organização" (ibidem) da cidade de Pouso Alegre.

O primeiro material que recortamos para análise é uma imagem posta em circulação no Facebook pela página Pouso Alegre da Depressão. As páginas ditas da Depressão têm como característica o fato de produzirem formulações que jogam com acontecimentos e com aspectos repudiados pela população de uma determinada cidade. Ressaltamos que é de acordo com essa formação discursiva da Depressão que o São Geraldo está sendo significado da forma como veremos na imagem a seguir, que consiste em uma montagem em que o desenho $O$ Rei Leão é parodiado. Vejamos.

Nesta imagem, Mufasa, o Rei Leão, e Simba, seu filho, podem ser compreendidos de diferentes modos. Guardaremos que se trata de um ser mais experiente significando a cidade/reino para um jovem. O pai diz: tudo o que o sol toca é Pouso Alegre. O filho expressa seu espanto (Wow), e em seguida questiona: Mas e aquele lugar escuro? Seu pai responde: é o Aterrado. O bairro é posto para o jovem como uma região que jamais deve ser visitada, visto que ele deve percorrer somente os domínios do seu reino. O São Geraldo, quer dizer, o Aterrado, é colocado como um local que não pertence a Pouso Alegre.

As terras do reino são extensas, ultrapassam a paisagem que pode ser observada de cima de uma colina. Os seus contornos não estão sendo postos nos pontos mais longes, não estão sendo dados de acordo com a distância geográfica, pois tudo o que o sol toca faz parte do reino. Eles estão sendo estabelecidos no interior das próprias terras, e para fazer essa delimitação do território, o Rei Leão utiliza a relação entre a luz e a sombra. A luz está permitindo a definição dos limites: os locais iluminados são parte do reino e o espaço escuro não. Mas o sol não estar atingindo o Aterrado não é o motivo pelo qual ele está posto como não pertencente à cidade, por esta via, a escuridão sobre ele é somente a 
alternativa escolhida para que se possa explicar o modo como para o pai, o bairro, mesmo estando localizado "dentro", permanece "fora" da cidade. As fronteiras não estão sendo dadas de um modo em que os seus contornos "exteriores" podem ser apontados. Mufasa não mostra o reino para seu filho dizendo que ele é, por exemplo, "tudo o que há entre estas colinas e o rio", ou simplesmente "tudo o que podemos ver", sendo que um dos lugares que assim seria incluído nesse domínio para ele não faz parte.

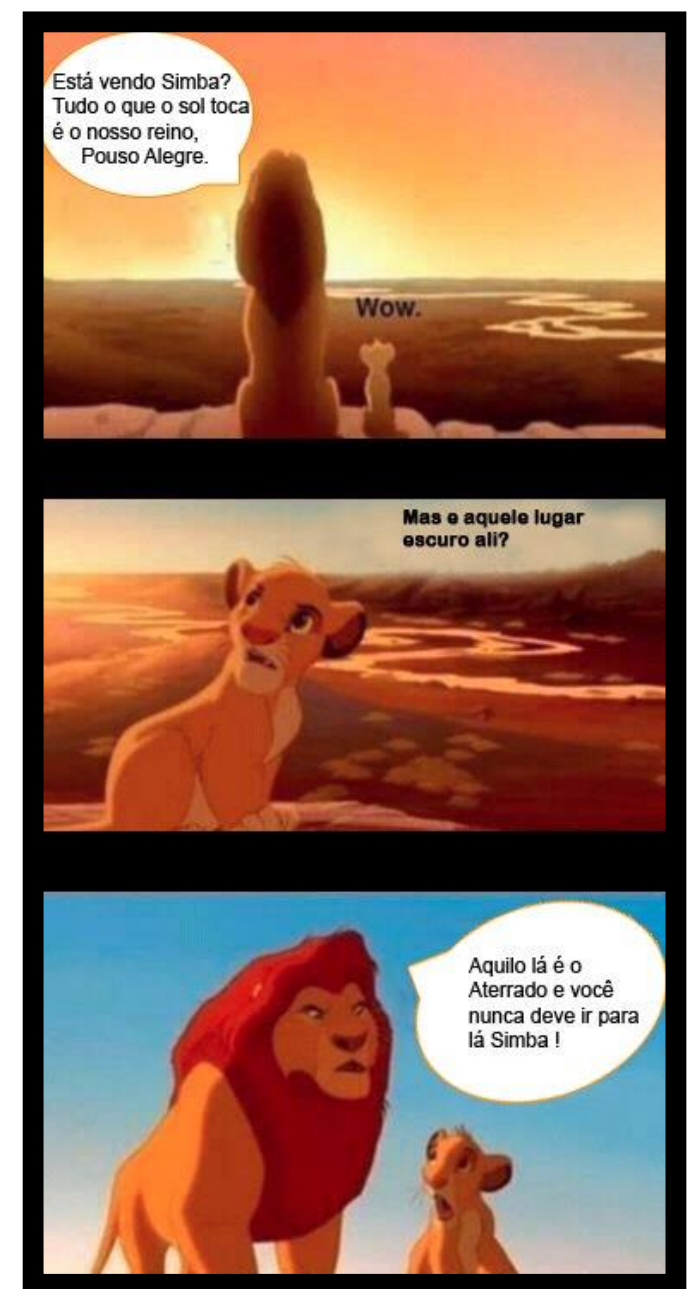

Em seu discurso, o pai busca a "organização" da cidade (na luz), já no discurso do filho é o "real da cidade" que (se) significa (na escuridão), "desorganizando" o "imaginário urbano" do pai. Notamos que a explicação a ser realizada por ele e compreendida pelo filho é confusa. Em relação ao pai, percebemos essa dificuldade na sua escolha de utilizar o sol como um ponto de referência para se fazer a demarcação da cidade, uma vez em que as coordenadas geográficas a partir dos elementos da paisagem não favorecem o tracejo desse limite. E quanto ao filho, ela é significada nas diferentes expressões que ele apresenta: primeiramente Simba contempla a vista; em seguida, quando percebe que há uma área que não está sendo atingida pelo sol, mas que está no interior do reino, confuso, sob um olhar de insegurança ele faz um questionamento; e no momento em que recebe a resposta de seu pai, que confirma a contradição que produziu a sua dúvida, ele se espanta. Uma paráfrase deste diálogo, que expõe o que estamos compreendendo poder ser: 
Pai: Tudo o que o sol toca é o nosso reino.

Filho: Mas e aquele lugar escuro ali?

Pai: Eu disse somente o que o sol toca!

Filho: Mas ele está no meio do reino.

Pai: A questão não é onde está, sim o que é3.

Filho: Como assim?

Pai: Ele está entre o reino, mas não é parte dele.

Filho: Por quê?

Pai: Porque é o Aterrado.

Filho: Nossa!

As diferentes interpretações do Aterrado podem ser observadas ainda quando analisamos a dêixis daquele discurso. O filho menciona o bairro como aquele lugar escuro ali, e seu pai diz que aquilo lá é o Aterrado. Com o termo aquele, Simba acusa o distanciamento entre ele e o bairro, que é inevitável, visto que no momento em que elas são proferidas ele está no alto de um monte. Porém, com a expressão ali, ele indica ainda que essa distância entre eles é curta. Ele aponta para o bairro tomando como referência a geografia da cidade, e mostra a proximidade que há entre ele e o Aterrado, na medida em que esse está localizado no centro da cidade em que ele vive. Na palavra escuro ele se mostra intrigado por causa da relação sol/sombra, e de acordo com o seu parâmetro ele não está longe nem de um e nem de outro. Ou seja, Simba faz significar que o espaço da cidade é tomado por "luz" e por "escuridão", e que isto é uma questão geográfica. Escuridão aqui é simplesmente "ausência da luz do sol".

O Rei Leão (se) afasta (d)o bairro. A significação do precipício entre eles extrapola a do que há da colina para a planície da cidade. Para ele, o Aterrado está localizado lá (longe). Ele sobrepõe a distância geográfica pela formulação de um abismo simbólico que produz o afastamento social entre o bairro e a cidade. Para o pai, que se filando ao "discurso (do) urbano" coloca a "luz" e a "sombra" como uma metáfora para dizer o que é (ou não) espaço urbano, "escuro" não é "ausência de luz", mas "carência de organização".

Outro ponto em que podemos observar essa exclusão do Aterrado de Pouso Alegre está na forma como o Rei Leão se refere ao mesmo. Enquanto Simba o aponta como um lugar, o seu pai retira o bairro desta categoria. Para ele, o Aterrado é aquilo lá. Como dissemos mais acima, para o filho, o local estar escuro não necessariamente o difere do Reino, pois se trata simplesmente de um lugar que não está sendo atingido pela luz solar naquele momento. Ou seja, o que ele avista ali é um bairro, é a cidade, é um lugar. Já nos dizeres do pai, a indeterminação sobre o que é o Aterrado, posta na palavra aquilo, incide sobre o atributo de lugar produzindo o efeito de contraposição a esta declaração de Simba. Desse modo, ele não só desintegra o bairro da cidade, além disso, ele acaba por defini-lo pela negação da interpretação do filho. Assim, para o pai, Aterrado é "qualquer coisa" menos um lugar. Quer dizer, é um não-lugar, um não-bairro, ou, como o seu discurso de um modo geral faz significar, é um não-reino, um não-Pouso Alegre.

\footnotetext{
${ }^{3}$ Ao dizermos em nossa paráfrase que "a questão é o que aquele lugar é", o que pretendemos é destacar que para a posição-sujeito inscrita neste discurso o que importa é a projeção feita pelo imaginário urbano sobre o Aterrado. Ou seja, nessa perspectiva, "o que é", já é um resultado do discurso de organização da cidade.
} 
O segundo material que analisamos consiste em textos que foram obtidos no site da Desciclopédia que é dedicado a Pouso Alegre. Na página ${ }^{4}$, as sequências que recortamos, que são aquelas em que o bairro é mencionado, se encontram nos tópicos Fatos Marcantes, Bairro e População.

1 - 2003 - Manos do Aterrado atacam guarnição dos Bombeiros que tiveram que ser resgatados pelo então desconhecido e ainda Cabo, o capitão Nascimento.

2 - CASCALHO: a melhor porra de bairro de PA q só perde pros mano do aterrado em manice.

3 - Possui também uma enorme quantidade de adolescentes EMOS, NERDS e AFINS, além dos "TEMIDOS" Manos do Aterrado. (Maloqueiros e Abas Retas) - Vale lembrar que o "TERRADO" vai dominar o mundo! (ao menos é isso o que os Terradenses pensam).

Essas formulações chamaram a nossa atenção também pelas diferentes nomeações que aí estão sendo postas para os moradores do Aterrado e para o próprio bairro. Nelas podemos notar como "o modo como se dispõe o espaço é uma maneira de configurar sujeitos em suas relações, em suma, de significá-los" (ORLANDI, 2012, p. 199). Analisando a questão da "denominação" nestes enunciados, observamos ainda como ela "se interpõe como um corpo opaco entre o corpo do sujeito e o corpo da cidade" (COSTA, 2012, p. 146), isto é, como as nomeações dos sujeitos moradores também significam o espaço do bairro e vice-versa.

Nos dois casos iniciais, notamos que o foco não está direcionado ao Aterrado, ou sobre a sua população. No primeiro, os Manos do Aterrado são colocados como aqueles que teriam realizado um dos "fatos marcantes" de Pouso Alegre, e no segundo, eles são citados como um parâmetro para caracterizar o bairro Cascalho. De uma forma geral, a expressão "manos" significa de modo distinto, dependendo da formação discursiva em que está inscrita. Aqui, ao menos na sequência 1, o seu efeito de sentido à liga ao de criminoso. Além de apontar os Manos do Aterrado como os responsáveis por atacar a guarnição dos bombeiros, a intervenção da polícia é posta como a condição em que eles puderam ser resgatados. Indo mais longe, percebemos que os sujeitos em questão são significados como criminosos de alto risco, pois vemos que não se trata de qualquer policial que interveio no fato descrito, mas do então desconhecido e ainda Cabo, o capitão Nascimento, que é a personagem do filme Tropa de Elite, o capitão do Batalhão de Operações Policiais Especiais do Rio de Janeiro. Isto é, um policial que, no filme, trata exclusivamente de criminosos de alta periculosidade.

E são esses os sentidos que também sustentam a segunda passagem. Para produzir um efeito de bairro perigoso para o Cascalho, é dito que ele só perde pros mano do aterrado em manice. A palavra que significa os sujeitos passa a nomear ainda as suas práticas: e criminoso está para crimes, assim como mano está para manices. Eis o deslizamento de crimes para manices, determinado pelo sentido de mano como um criminoso que foi significado na primeira sequência. Este é um processo discursivo em que vemos, como diz Pêcheux (2012), que um enunciado tem "pontos de deriva" que podem deslizar constituindo outro enunciado. Considerando este deslizamento, uma das paráfrases deste discurso pode ser a seguinte: o Cascalho é um bairro perigoso, só não é

\footnotetext{
${ }^{4}$ Disponível em http://desciclopedia.org/wiki/Pouso_Alegre. Acessado no dia 12 de março de 2014.
} 
mais perigoso do que o Aterrado. Antes, é dito que o Cascalho é a melhor porra de bairro de PA. Assim, observamos que o melhor, nestas condições de produção, significa de um modo peculiar, pois o que está sendo dito não é que o Cascalho é o melhor bairro, mas sim a melhor porra de bairro. A palavra porra, em relação com o sentido de crimes, define que de fato o que está em questão não é o melhor bairro, mas a melhor porra de bairro, que também poderíamos entender como o pior dos piores bairros. Outra paráfrase cabível seria: entre os piores bairros de Pouso Alegre, o Cascalho é (quase) o pior, só perde para o Aterrado.

A terceira formulação também se relaciona com estes sentidos. Nela, a princípio, observamos ser criada uma oposição entre diferentes moradores de Pouso Alegre. De um lado, são colocados os adolescentes EMOS, NERDS e AFINS, grupos que no imaginário social são tidos como frágeis e que, neste contexto, podemos dizer ainda inofensivos, e do outro, os Manos do Aterrado, indicados como temidos. Uma ambiguidade é instaurada sobre o sentido de "perigosos" que está significando nas passagens anteriores. Isso acontece devido à inserção das aspas entre a palavra "temidos". Desse modo, eles surgem tanto como temidos, quanto como Manos que não causam nenhum temor. Ou melhor, é posto que por uma parte dos pousoalegrenses eles são interpretados como ameaçadores, mas que por outra são vistos como inofensivos, assim como os grupos que os antecedem na escrita da frase. Nessa direção, o sentido de "perigosos" é ironizado. Enquanto Maloqueiros e Abas Retas, eles não são postos como "criminosos perigosos" e nem definidos pelas atividades que realizam, mas sim pelo que o sujeito que produziu esse discurso acredita ser o modo como eles se trajam. Por fim, se significa o imaginário sobre esta forma de vestir, que naqueles que a associa com a criminalidade desperta medo, e nos que não o fazem gera o deboche.

Na última parte do enunciado é dito: Vale lembrar que o "TERRADO" vai dominar o mundo! (ao menos é isso o que os Terradenses pensam). Já não é mais Aterrado, mas somente Terrado. De acordo com a historiografia de Pouso Alegre, antes de receber o nome São Geraldo, o bairro já era conhecido como Aterrado, isso porque começou a se formar em uma área que foi aterrada várias vezes. No discurso que estamos analisando, com a elisão da letra "a", de certa maneira também sai de cena essa ligação do nome do bairro com a palavra "terra", pois resta "terrado", que na etimologia popular relaciona-se com o termo "terror". Além dessa modificação na forma de nomear o bairro, nos atentamos também com a mudança que ela acarretou no modo como os moradores passaram a ser referidos, relação esta que nos permite observar de uma outra forma a intrínseca ligação que há entre a cidade e os sujeitos (ORLANDI, 2012), neste caso pela denominação (COSTA, 2012). Aterrado deslizou para Terrado, e Manos do Aterrado para Terradenses. Mas como não se trata de "manos terradenses", o que é designado são os habitantes do bairro de uma maneira geral. Isto é, com a retirada da palavra manos, que delimitava a parte da população, e com o surgimento de terradenses, o enunciado começa a abranger todos os seus residentes. E se Aterrado está ligando-se à "terra", como falamos há pouco, podemos dizer que manos (do Aterrado) também está. Logo, assim como em Terrado há um deslize do sentido de terra para o de terror, um dos pontos de deriva de terradenses leva à identificação dos morados do bairro como terroristas. Essa relação fica ainda mais marcada considerando que está sendo dito que o que os Terradenses pensam é que o Terrado vai dominar o mundo, ou seja, que a dominação do mundo, que implica subjugar outras nações pela guerra, pela luta, é posta como uma pretensão do bairro. 
Aqui, podemos ver que a "denominação", como diz Costa (ibidem, p.146), "funciona no percurso dos sentidos como um vetor ideológico", que "os carrega no trajeto entre espaços e sujeitos", pois observamos como a significação posta nessa forma de nomear os moradores como Terradenses acaba produzindo outros sentidos para o bairro também. Com esta expressão, é feita uma separação entre os moradores do São Geraldo e os outros de Pouso alegre que se sustenta justamente na desagregação aí realizada entre o bairro e a cidade. Afinal, Terradenses seria cabível para identificar a nacionalidade ou a naturalidade de uma pessoa. O brasileiro o é porque nasceu no Brasil, assim como o mineiro, por ser oriundo de Minas Gerais. Quem foi gerado em Pouso Alegre é pousoalegrense. Viver em um determinado bairro não modifica tais referências. Logo, com tal termo, o Terrado é colocado ao nível de uma nação, de um estado ou de uma cidade, que tem como seus habitantes os terradenses, ou seja, ele é desmembrado da cidade, dado como tendo a sua própria população.

\section{Discurso do bairro}

Passamos agora ao "discurso do bairro". Conforme discorremos inicialmente, nesta etapa objetivamos compreender como o São Geraldo se significa em seu próprio discurso. Para isso, analisamos recortes de uma matéria do jornal Folha do Vale, publicada no dia 10 de junho de 2011 em Pouso Alegre. Nela é noticiado um acontecimento que ficou denominado Semana do Bairro, promovido pelos moradores do São Geraldo e pelos integrantes da Associação do bairro chamada Viva Geraldo!. Esta reportagem nos possibilitou tanto analisar as ações realizadas na Semana do Bairro como dizeres dos moradores e representantes do São Geraldo.

O evento Semana do Bairro foi um conjunto de intervenções feitas entre os dias 5 e 11 de maio de 2011. Resumidamente, segundo a matéria, essas ações foram uma caminhada pelo São Geraldo, a realização de uma roda de capoeira, o plantio de árvores e o recolhimento de materiais recicláveis em seu espaço, e a participação de moradores e representantes do bairro em uma reunião do projeto de Orçamento Participativo do São Geraldo e em uma seção na Câmara dos Vereadores de Pouso alegre, na qual eles fizeram o uso da Tribuna para expor determinas reivindicações. Observando a realização destas atividades, as quais também estamos considerando como uma das materialidades do "discurso do bairro", percebemos que o São Geraldo possui diversas demandas e, ao analisar outros dizeres de moradores e representantes do bairro que estão na matéria, vemos que elas passam por duas vertentes: as intervenções administrativas no espaço do São Geraldo e a mudança no modo como ele é visto pelos seus próprios moradores e principalmente pelo restante da cidade. Percebemos que esta última questão, referente à sua imagem, é a mais significativa para os fins da campanha. Vemos como o primordial não é somente cuidar do bairro, mas também mostrar que ele é um local que pode ser melhorado.

Segundo o jornal, as propostas direcionadas à Câmara Municipal foram feitas com o objetivo de contribuir para que o bairro tenha uma imagem positiva. Ele cita que para um dos membros da Associação do bairro que discursaram na Tribuna da Câmara, o diretor da escola CIEM São Geraldo naquele período, a caminhada e o plantio de árvores se justificam no fato de que é preciso mostrar que o bairro pode ser mais cuidado $e$ 
preservado. Quer dizer, tais atividades foram empreendidas não somente com a finalidade de tratar aquele espaço diretamente, mas sobretudo a de formular para os pousoalegrenses e, considerando a histórica "falta do Estado" (ORLANDI, 2012) no bairro, acreditamos que principalmente para os administradores da cidade, sentidos como esses: o São Geraldo também é receptivo para melhorias, para investimentos infraestruturais. Ou seja, de uma maneira geral, o evento se significa como um argumento para que a administração pública possa entrar e atuar no bairro.

Ao pensarmos nas condições em que a caminhada pelo São Geraldo é realizada, considerando que, como diz Canguilhem (1990 apud PÊCHEUX, 1994), "o sentido é sempre relação à", percebemos que, entre outros, ela produz os sentidos de encontro, de ocupação, de festa, de passeio pelo bairro. De uma forma ampla, ao reunir pessoas em trânsito pelas ruas, assim como o próprio nome da Associação Viva Geraldo!, o que a caminhada em suas condições de produção faz significar é: há vida no São Geraldo! E assistir a uma empreitada para demonstrar para os habitantes de uma cidade que há vida em um bairro, que uma rua pode ser um local de passeio, ou mesmo para as outras atividades, produz a possibilidade de compreendermos que esses sentidos do local em questão permanecem no campo do "sem-sentido" e do "não-sentido" 5 . Tais sentidos, que já teriam sido produzidos com construção das ruas, das casas, com a própria formação do bairro, já não significam mais, ou jamais significaram, dependendo da formação discursiva em que o São Geraldo se inscreve. Eis a razão da necessidade de "mostrar", ou melhor, de (res)significar esse espaço, de fazer com que o seu "irrealizado advenha formando sentido" (PÊCHEUX, 1980, p. 17). O mesmo vale para o plantio de árvores, por exemplo. Se em outros locais de Pouso Alegre, uma praça, uma calçada, ou um canteiro são alvos do cultivo de plantas, então esses locais já foram significados para a cidade como lugares passíveis de receberem essas intervenções. Sentidos que, em relação ao São Geraldo, como a Semana do Bairro nos indica, não (se) significam (mais).

Com a análise de outros recortes observamos melhor qual é o principal público que com a campanha realizada durante o evento a Associação Viva Geraldo visa atingir, notando o modo como o seu trabalho incide principalmente sobre os sentidos do bairro para outros moradores da cidade. De acordo com a matéria, a Associação trabalha no sentido da melhora do bairro e da visibilidade do São Geraldo, no restante da cidade (grifos nossos). Embora o bairro esteja em uma região central, o que está posto é que ele não é visível para o restante da cidade como querem os seus moradores. Porém, o que significa aqui não é que ele está geograficamente distante da cidade, o que se busca não é que o restante da cidade tenha o bairro em seu campo de visão. Nesta ocasião, ele surge como "irrealizado" (ibidem), a “(in)visibilidade” está no nível simbólico. Aqui, ser visível é ser (fazer) sentido. São essas as observações que nos permitem jogar com tais palavras e deslocar o sentido de "procedimentos metodológicos" da Associação, tal como colocado na frase do jornal, para o de "objeto" de seu trabalho, dizendo: a Associação trabalha (n)o sentido da melhora do São Geraldo.

Poderíamos acrescentar que isso é feito com a finalidade de se fazer significar sentidos do bairro já experimentados pelos seus moradores para aqueles que não o são. Pelo restante da cidade, as ruas do bairro, as suas praças, não teriam sido interpretadas como locais de passeio, de festa, de ocupação, etc. Para os administradores de Pouso

\footnotetext{
${ }^{5} \mathrm{O}$ "sem-sentido" é o sentido que já significou e não significa mais, ele "refere ao que já não faz sentido",
} enquanto o "não-sentido" indica "o que virá a fazer sentido" (ORLANDI, 2010, p. 18). 
Alegre, ele não teria se significado como um local de investimento público. Assim, o que a nossa análise faz compreender é que sentidos como estes, realizados na formação discursiva do São Geraldo, que pertencem ao "real do bairro" e que para seus habitantes são constitutivos do mesmo, estão como "não-sentido" na formação discursiva de outros pousoalegrenses e da administração do município. "Irrealizados", que podem (ou não) vir a significar.

A percepção de que os realizadores da campanha em prol do bairro tomam como objetivo primordial o trabalho dos seus sentidos na cidade, nos mostra que o modo como o São Geraldo é interpretado em Pouso Alegre não agrada os seus moradores, que, para o bairro, ele é visto de uma maneira negativa pelo restante da cidade. E observamos como o intuito com o evento é justamente afirmar sentidos positivos do São Geraldo para outros pousoalegrenses. Com a análise do discurso do representante da Associação Viva Geraldo, o diretor da escola CIEM São Geraldo em 2011, podemos perceber que esse aspecto de positividade resume-se na demonstração de que o bairro não se distingue dos outros em relação às suas condições de existência. Ou, dito de outro modo, vemos como em seu discurso, o bairro é positivo porque ele é semelhante aos demais da cidade, que esse é o sentido da positividade que aí está se significando. Em seu pronunciamento na Tribuna da Câmara dos Vereadores, o diretor disse: (o São Geraldo) "não teve chance de se projetar por ser área de baixo valor econômico, margeado por dois rios, alagável nas épocas de vazante do Mandu e Sapucaí Mirim, e passou a ser um lugar para os menos afortunados pela vida". A matéria esclarece ainda que, para ele, o bairro é um retrato da insensibilidade dos homens públicos que passaram pela administração de Pouso Alegre.

Vemos o modo como os momentos em que algumas condições do São Geraldo são destacadas nesse discurso ocorrem em alternância com palavras que funcionam como justificativas para elas. No primeiro enunciado, há as afirmações de que o bairro é uma região pouco valorizada economicamente e que é um local de moradia de uma população de baixa renda. Essas considerações indicam aspectos constitutivos do bairro, e que o diferencia de outros em Pouso Alegre. Em o São Geraldo "não teve chance de se projetar", também se coloca que ele está em um plano diferente de acordo com a questão econômica. Porém, esses dizeres desempenham o papel de explicar tal situação. Modificando a ordem daquela frase, e trazendo para o plano do dito os termos "isso porque", que no discurso em questão estão como "não-ditos" (ORLANDI, 2009), ele ficaria assim: o bairro é um lugar para os menos afortunados pela vida, isso porque é uma área de baixo valor econômico, isso porque não teve chances de se projetar, isso tudo porque é margeado por dois rios, alagável nas épocas de vazante do Mandu. Dessa forma, o que estamos destacando é que na ordem desse discurso, as justificativas aí presentes estão significando ao modo de uma anulação específica das diferenças do São Geraldo. Em várias passagens temos a afirmação de que ele se diferencia na cidade. Mas, pela explicação de que tudo isso ocorre porque ele é "margeado por dois rios, alagável nas épocas de vazante do Mandu e Sapucaí Mirím”, a situação de desigualdade do bairro é caracterizada de uma forma precisa, ao passo em que é fundamentada pela sua localização. Ou seja, a razão dada para justificar as atuais condições do São Geraldo é da ordem das causas naturais, e não da do social, a qual colocaria em questão as formas pelas quais a cidade foi/é administrada. Enfim, o fato é que, se por um lado é posto que o São Geraldo é diferente, por outro ele é definido como semelhante, pois, o que aquele discurso faz significar é que ele é igual a qualquer outro bairro que estivesse sob tais determinações geográficas seria: diferente. 
Gostaríamos de sublinhar ainda que, na materialidade desse discurso, ser uma área de baixo valor econômico surge como uma causa para o São Geraldo não ter tido chance de se projetar, e não como um efeito da atuação dos administradores da cidade. Outra paráfrase daquele discurso que propomos é: o bairro é um lugar para os menos afortunados pela vida, isso porque é uma área de baixo valor econômico, isso porque não teve chances de se projetar, isso tudo porque os homens públicos que passaram pela administração de Pouso Alegre não trataram das consequências dele ser margeado por dois rios, alagável nas épocas de vazante do Mandu e Sapucaí Mirím. Com esta outra modificação, o que sublinhamos é que a falta que faz com que o bairro seja uma região de baixo valor econômico, não é a de oportunidade (chance), assim como no discurso do diretor, mas sim a do Estado, que não efetivou intervenções para atender às necessidades do bairro, decorrentes da sua localização entre os rios.

Outro ponto que analisamos é o lema estabelecido pela Associação Viva Geraldo. $\mathrm{Na}$ matéria do jornal, ainda sobre a reunião na Câmara Municipal, por fim é dito: concluindo, os representantes do bairro afirmaram que "a partir desta semana, o lema do Viva Geraldo! é 'Eu amo o bairro São Geraldo. Eu cuido do bairro São Geraldo". Notamos como esse lema traz o "pré-construído" (PÊCHEUX, 2009) de que "quem ama cuida", funcionando pela determinação de alguns sentidos do "amar" que acaba significando aí como "cuidar". No slogan, esse dizer ("quem ama cuida") é reinscrito, e recebe a inserção de alguns termos que o contextualiza na cidade de Pouso Alegre. Neste caso, surgem novas colocações relacionadas à situação em questão, sendo estas praticamente duas: "eu amo o bairro São Geraldo"; "eu cuido do bairro São Geraldo". As afirmações presentes no lema não ultrapassam a de que um alguém ama o São Geraldo, a de que um alguém cuida do São Geraldo e a de que "quem ama cuida", que surge como efeito interdiscursivo ligando essas duas proposições e tornando um só o sujeito que ama e o que cuida do bairro. E assim, o que se significa nesta ocasião é que alguém ama e, consequentemente cuida do bairro. Vemos que o que o slogan da campanha precisamente faz é colocar ao nível da formulação do discurso certos sentidos do São Geraldo "silenciados" (ORLANDI, 2007) em Pouso Alegre. Um possível enunciado de base para eles seria: "O São Geraldo é amado". São sentidos de amor em relação ao bairro, que constituem o seu discurso, e que seus moradores e representantes, neste caso, procuram fazer significar também fora dele.

Considerando as colocações de Payer (2006, p. 53), que nos diz que a formulação dos sentidos da "memória silenciada" pode criar condições para que venham significar aqueles que ainda "não foram ou não são contemplados como possíveis no conjunto do dizível", compreendemos que o lema da campanha formula certos sentidos constitutivos do bairro, cumprindo o objetivo de produzir a possibilidade de que eles se inscrevam também na formação discursiva dos não-moradores do mesmo. Não estamos afirmando que esses determinados sentidos "não foram ou não são contemplados como possíveis no conjunto do dizível" (ibidem), mas que eles são sim "impossíveis", "irrealizados" em uma região específica desse conjunto, que é a da formação discursiva dominante em Pouso Alegre nos discursos sobre o São Geraldo. Assim, do lugar possível, o discurso do bairro, o dizer "Eu amo o bairro São Geraldo. Eu cuido do bairro São Geraldo" é formulado, para que os sentidos que possam derivar da sequência "o São Geraldo é amado" se inscrevam na cidade. E como a memória "não restitui frases escutadas no passado mas julgamentos de verossimilhança sobre o que é reconstruído pelas operações de paráfrases" (ACHARD, 2010, p. 16), entendemos que essa inscrição já cria as condições 
para que sentidos de amor, de cuidado, de afeto, enfim, para que "não-sentidos" do São Geraldo venham a constituir também a formação discursiva do restante da cidade.

Por fim, a última sequência que analisamos é outro recorte do pronunciamento do diretor da escola CIEM São Geraldo que, segundo o Jornal, disse ainda: tráfico de drogas, prostituição e violência não são problemas isolados do bairro. Tendo em consideração a distinção que viemos ressaltando, entre os sentidos do São Geraldo na formação discursiva do bairro, neste momento podemos perceber sentidos da formação discursiva dos não-moradores que também se fazem presentes no discurso do São Geraldo. Na passagem em questão, eles se encontram através dos pré-construídos que nela são retomados. Estes, de acordo com a formulação, se relacionam à significação do bairro como o local exclusivo em que tráfico de drogas, prostituição e violência são praticados na cidade. A existência de tais atividades no São Geraldo não é negada, pelo funcionamento daquele discurso ela é até mesmo admitida, significando como uma negatividade do bairro, que adquire esse sentido ao passo em que essas ações são reconhecidas enquanto problemas do mesmo.

E sobre esse primeiro pré-construído, um outro é retomado, isso nas seguintes palavras: não são problemas isolados do bairro. Aqui, notamos novamente que o trabalho no sentido do São Geraldo na cidade de Pouso Alegre, pelo qual se busca a melhora do bairro no restante da cidade, ocorre especificamente através de uma sobreposição de sentidos, que em última instância produz o efeito de igualdade do bairro. Diversa é a maneira como essa sobreposição é realizada, pois oscila de acordo com a situação. Inicialmente, ela está direcionada aos sentidos do bairro e, em seguida, aos de outros espaços da cidade. No instante em que o pressuposto é a positividade (de outros bairros), como a valorização econômica ou a boa infraestrutura, a sobreposição é a das suas diferenças, e o que ela faz significar é: o São Geraldo é igual a outros bairros. Mas, ao passo em que a hipótese é a da sua negatividade, o que é sobreposto são as diferenças entre os próprios bairros da cidade, e os sentidos produzidos neste momento são os de que: outros bairros são iguais ao São Geraldo. No primeiro caso, o bairro é igualado aos demais, já no segundo estes é que são assemelhados a ele.

Uma das compreensões que o discurso do bairro nos permite é a de que a negatividade que ele busca negar, assim como a positividade que ele procura afirmar, também está girando em torno da diferença e da igualdade entre o São Geraldo e os outros espaços de Pouso Alegre. Para o bairro, nos discursos que analisamos, a negatividade é referente à sua definição como um espaço único, na medida em que os fatores que formam a sua especificidade, neste caso, são desfavoráveis para ele. É assim que temos o seguinte pré-construído retomado pela negação em seu discurso: "o São Geraldo é diferente”.

\section{Considerações finais}

A partir das nossas análises, destacaremos alguns aspectos da discrepância de sentidos que há entre o "discurso sobre" e o "discurso do bairro".

Como dissemos inicialmente, os discursos sobre o São Geraldo estão funcionando como "discurso (do) urbano" (ORLANDI, 1999, 2004). Na página Pouso Alegre da 
Depressão e na Desciclopédia, pudemos observar isso de diferentes formas. No primeiro caso, o personagem Rei Leão, através de um jogo entre luz e escuridão, procura explicar para o seu filho que, embora o Aterrado esteja entre os outros bairros da cidade, ele não está "dentro", ele não pertence a Pouso Alegre. Ou seja, se exclui uma parte constitutiva da cidade, que é da ordem do seu "real". No imaginário presente nesse discurso, a delimitação do que é (ou não) a cidade é produzida através de uma organização de Pouso Alegre em que o Aterrado fica de fora. No discurso do site Desciclopédia, vemos a cidade ser organizada de uma maneira similar. Novamente, o São Geraldo, aqui sendo chamado pelo seu nome popular Aterrado, ou ainda como Terrado, é separado da cidade. Primeiramente é destacada uma parte dos moradores do bairro que é definida como criminosos, em seguida, ele é colocado como sendo o pior bairro da cidade e, por fim, sendo nomeado como Terrado, e os seus moradores como Terradenses, ele é significado como se fosse uma Nação ou um Estado próprio, enfim, como um território alheio à Pouso Alegre. Discursos sobre o bairro: ambos se filiando a uma formação discursiva na qual os sentidos sobre a cidade que nela são produzidos fazem uma sobreposição da "materialidade", do "real" do São Geraldo a partir de um "imaginário urbano" de "organização" de Pouso Alegre no qual o bairro é excluído.

Muitos sentidos que nesses dizeres sobre o São Geraldo estão silenciados, aparecem formulados em seu discurso. Neste, o "real" do bairro, o "real" da cidade (IBIDEM) são significados. Notamos como ele não separa a si próprio, mas, ao contrário, se reafirma como uma parte integrante de Pouso Alegre, impossível de ser desmembrada, e que não deve ter um tratamento diferenciado do que recebe os demais bairros, tanto por outros habitantes como pela administração do município, assim como em sua compreensão vem ocorrendo. De acordo com Orlandi (2012, p.230), em relação ao Estado, em nossa sociedade, a "falha" e a "falta" estão intimamente ligadas. A autora nos diz que a "falha" é "estruturante do Estado", e que a sua "falta" é "uma forma de presença em condições de produção em que deveria estar lá mas não está, falta". O São Geraldo, em seu discurso, expõe justamente essa "falha do Estado", fazendo significar a sua "falta" no bairro em diversos aspectos e o modo como ela o constitui na cidade, individuando a população pousoalegrense de diferentes formas. Ele também faz significar a marginalização que daí decorre para com o bairro, e nos permite compreender como determinados sentidos do São Geraldo estão como "irrealizados" (PÊCHEUX, 1980) em formações discursivas como as que vimos anteriormente nos discursos sobre ele.

Por fim, gostaríamos de concluir com a consideração de que, em nossa compreensão, o discurso do bairro, no caso que analisamos, não metaforiza os sentidos das suas reivindicações com palavras que fazem eles se inscreverem na formação discursiva da administração da cidade, que é a esfera onde as melhorias do São Geraldo almejadas deveriam começar a ser efetivadas. Em uma das falas do representante do bairro que está posta no material que analisamos, ele não diz que o "São Geraldo pede para ser visto com seriedade, tratado com a responsabilidade que uma administração municipal deve ter", ou que "é uma obrigação da administração da cidade realizar melhorias no bairro, assim como é feito no restante da cidade", mas sim que "o bairro pede para ser visto com carinho e não piedade". No caso do lema "Eu amo o bairro São Geraldo. Eu cuido do bairro São Geraldo!”, da Associação do bairro, o devido “cuidado" que o bairro deve receber é posto como uma incumbência da própria população da cidade, como um encargo das práticas assistencialistas e não do Estado. O "cuidar", nesta ocasião, é colocado como um compromisso exclusivo daqueles que "amam" o bairro, e não 
precisamente dos órgãos públicos que o administram. Sentidos que seriam outros se as palavras fossem, por exemplo: "ainda que você não ame o São Geraldo você deve respeitá-lo!". Lembremos novamente o enunciado de que o bairro é um retrato da insensibilidade dos homens públicos que passaram pela administração de Pouso Alegre. Nele, não se remete a atual situação do São Geraldo à histórica falta de responsabilidade que os governantes tiveram para com o bairro. Gesto este que poderia fazer o funcionamento deste discurso passar do desabafo ao protesto. Aqui, as condições precárias do São Geraldo estão sendo atribuídas à falta de algo que de certa forma é opcional para um administrador, e não para aquilo que é obrigatório até mesmo para o político mais indiferente em seu lado pessoal. Está dito que a questão foi devida à falta de sensibilidade, e não à falta de responsabilidade, de compromisso dos homens públicos para com a região que eles governaram.

Dada a afeição de moradores e representantes, o discurso do bairro segue na direção de afirmar para os pousoalegrenses os aspectos positivos que ele contém. Eles expõem o sentimento de amor que vivenciam pelo São Geraldo, clamam para que ele seja visto com carinho e não piedade, ou hostilidade. No entanto, nestas condições, a busca por mudanças fica na esfera sentimental, e não chega a atingir o plano político: o amor "ganha" a luta e o "político" vence a guerra.

\section{Referências}

ACHARD, Pierre. Memória e produção discursiva do sentido. Em: ACHARD, Pierre et al. O papel da memória. $3^{\text {a }}$. ed. Campinas: Pontes, 2010.

COSTA, G.C. da. Denominação: um percurso de sentidos entre espaços e sujeitos. Rua [on-line], n. 18, v. 1, 2012.

FARIA, R.M. Território urbano e o processo saúde-doença. Perfil territorial da saúde no São Geraldo, em Pouso Alegre (MG). Dissertação. Mestrado em Geografia, UNICAMP, Campinas, 2008.

GOUVÊA, O.M. A História de Pouso Alegre. Pouso Alegre: Gráfica Amaral, 2004.

ORLANDI, E.P. Discurso em Análise: sujeito, sentido e ideologia. Campinas, SP: Pontes, 2012.

Maio de 68: os silêncios da memória. Em: ACHARD, Pierre et al. O papel da memória. $3^{\text {a }}$. ed. Campinas: Pontes, 2010.

Análise do discurso: princípios e procedimentos. 8ª ed. Campinas: Pontes, 2009.

As formas do silêncio: no movimento dos sentidos. $6^{\mathrm{a}}$. ed. Campinas: Editora da Unicamp, 2007.

- Tralhas e troços: o flagrante urbano. Em: ORLANDI, E.P. (Org.). Cidade atravessada: os sentidos públicos no espaço. Campinas: Pontes Editores, 2001. 
N/O Limar da Cidade. Rua, número especial, Campinas, 1999.

PAYER, Maria Onice. Memória da língua: imigração e nacionalidade. São Paulo: Escuta, 2006.

PÊCHEUX, M. O discurso: estrutura ou acontecimento. 6ª . ed. Campinas: Pontes, 2012.

Semântica e Discurso: uma crítica à afirmação do óbvio. $4^{\mathrm{a}}$. ed. Campinas: Ed. da Unicamp, 2009.

Ler o Arquivo Hoje (1994). Em: ORLANDI, E.P. (Org). Gestos de Leitura. Campinas: Ed. Unicamp, 1997.

Delimitações, inversões, deslocamentos (1980). Caderno de Estudos Linguísticos, n. 19, Campinas, 1990.

Artigo recebido em: abril de 2017.

Aprovado e revisado em: setembro de 2017.

Publicado em: novembro de 2017.

\section{Para citar este texto:}

BARBOSA, André Silva. Discursos do/sobre o bairro São Geraldo/Aterrado na cidade de Pouso Alegre. Entremeios [Revista de Estudos do Discurso, on-line, www.entremeios.inf.br], Seção Estudos, Programa de Pós-Graduação em Ciências da Linguagem (PPGCL), Universidade do Vale do Sapucaí (UNIVÁS), Pouso Alegre (MG), vol. 15, p. 93-108, jul. - dez. 2017.

DOI: http://dx.doi.org/10.20337/ISSN2179-3514revistaENTREMEIOSvol15pagina93a108 